Research Article

\title{
The opinion of undergraduate medical students on current curriculum and teaching methodology of pharmacology in four medical colleges of India: a questionnaire based study
}

\author{
Manoj Kumar Saurabh ${ }^{1 *}$, Jitendra Agrawal ${ }^{2}$
}

Department of Pharmacology, GMERS Medical College,

Gotri, Vadodara, India

Received: 04 August 2015

Revised: 14 August 2015

Accepted: 03 September 2015

\section{*Correspondence to:}

Dr. Manoj Kumar Saurabh, Email: manojkumarsaurabh@ yahoo.co.in

Copyright: (C) the author(s), publisher and licensee Medip Academy. This is an openaccess article distributed under the terms of the Creative Commons Attribution NonCommercial License, which permits unrestricted noncommercial use, distribution, and reproduction in any medium, provided the original work is properly cited.

\begin{abstract}
Background: The objective of current study was to obtain an opinion from 2nd professional year passed medical students on current curriculum, teaching methodology and importance of pharmacology subject and to identify the area of improvement.
\end{abstract}

Methods: A set questionnaire was distributed among randomly distributed to 2nd year passed 100 undergraduate (UG) students to each of four medical colleges. They were instructed to tick out the best possible option of each question on the basis of their own perceptions. They are also asked to give suggestion to improve teaching and learning of pharmacology subject.

Results: Out of the 400 students, only 387 responses of students were suitable for data analysis. The majority of students $99.22 \%$ (384) were unsatisfied with the practical teaching. Teachings of preparing and dispensing types of exercises were irrelevant in today's clinical practice according to $87.78 \%$ of the students and were in favor of the deletion of such exercises from the curriculum. The analysis showed that $62.27 \%$ of the students were the opinion that animals should not be used in experimental pharmacology. More than half of the UGs (63\%) supported the use of computer assisted learning. All of the students were interested in the inclusion of case, problem and multiple choice based question discussions in the regular teaching classes followed by quizzes (31.78\%) and group discussions (14.47) while small number of students $(1.03 \%)$ were interested in the conduction of seminars.

Conclusion: There is an urgent need to reform the curriculum and practical teaching methods for fulfilling the objective of reading pharmacology.

Keywords: Undergraduate medical student, Curriculum, Teaching methodology, Pharmacology

\section{INTRODUCTION}

Pharmacology is one of the most progressive and constantly changing basic medical science subjects. It is taught in $3 \mathrm{rd}$, 4 th, and 5th semesters of our medical curriculum, and it is the backbone of rational therapeutics. Sound knowledge of this subject plays a very important role in developing a rational approach toward treating patients. It needs to be taught and learnt effectively so that the benefit of the rational use of drug and cost-effective treatment reach the grass root levels of the community with the help of basic doctor. The curriculum of pharmacology being implemented is currently lacks uniformity at different medical colleges due to the lack of a clear directive from the Medical Council of India (MCI) and has failed to keep pace with the rapid changes and the requirements of clinical practice. ${ }^{1}$ A famous pharmacologist also wrote, "the undergraduate (UG) medical curriculum in pharmacology, which has been a topic of intense debate among the pharmacologist unfortunately, has not undergone the requisite changes commensurate with the explosion of knowledge, techniques and new drugs have flooded the medical scene."

Didactic lectures, tutorials, and practical classes are the common methods of teaching in most of the medical colleges of India. The scientific curriculum of our subject and the innovative teaching methods would produce the vision and roadmap which can fulfill the academic objectives. It is believed that reviewing the teaching methods on getting feedback from the students and the modification of methodologies accordingly is very important for the UG medical teaching. ${ }^{3,4}$ 
Many previous studies were conducted in Indian setting related to the feedback of students regarding curriculum, teaching and evaluation methodology limited to one medical college only. Our survey was conducted in four medical colleges which included two governments and two self-financed (private) medical colleges of North India of different states to generate more effective data of survey. Many colleges of India has modified practical curriculum as per need of students.

Our objective behind this study were to assess: (a) whether the present curriculum fulfilled our objectives, (b) to find out area of modification needed in the curriculum, (c) to find out which teaching methods should be followed for better learning impacts on students.

\section{METHODS}

A set of questions was prepared by the authors with the help of teachers of their department and previous published studies which were undertaken for UG medical students. The questions were suitably modified according to the need of the study. All questions were separately validated by a pilot study on 20 students and result of the pilot study is not included in our study. The content of these questions ranged from issues on prevailing curriculum of pharmacology with various aspects of theory, pharmacy, and experimental practical, role of pharmacology subject in patients care and different methods of teaching of our subject. The students were also given freedom to offer their suggestions regarding the types of reforms which they felt were required in the curriculum as well as teaching methodology.

After obtaining the requisite permission from the Institutional Ethics Committee of Jhalawar Medical College (2013), the set of questionnaire was distributed among randomly selected hundreds 2nd Prof. MBBS passed UG students of 6th, 7th, and 8th semester belongs to each of four medical colleges of North India which were included two governments and two self-financed institutes. The majority of medical colleges of Rajasthan Bihar and Madhya Pradesh haven't modified practical teaching and curriculum as per need. So, we have included medical colleges of these states. The students were instructed to tick the best possible option for each question on the basis of their independent perception regarding pharmacology. The questionnaires were collected from all the students. Only set of complete responses from 2nd professional passed students were included for data analysis. The results were analyzed using excel.

\section{RESULTS}

Out of the 400 sheets of questionnaires that were distributed, $387(96.75 \%)$ were suitable for data analysis. It was observed that nine students did not attempt some of the questions and four students ticked more than one question. Hence,
387 students were included in our study. The response of questionnaires were given by the student are shown in Table 1 . The majority of students $(95.8 \%)$ were satisfied with the present curriculum of pharmacology theory, but almost all the students $99.22 \%$ (384) were unsatisfied with the practical curriculum. As far as the duration of 2nd professional MBBS is concerned half of the students $(50.17 \%)$ were satisfied but $42.11 \%$ of the students were in the opinion that reduction of the course duration by 6 months can be done.

Table 1: Students opinion about prevailing curriculum and teaching method of pharmacology.

\begin{tabular}{|c|c|c|}
\hline Questions for opinion & Response & $\mathbf{N}(\%)$ \\
\hline \multirow{2}{*}{$\begin{array}{l}\text { Satisfied with theory } \\
\text { curriculum }\end{array}$} & Yes & $368(95.09)$ \\
\hline & No & $98(4.91)$ \\
\hline \multirow{2}{*}{$\begin{array}{l}\text { Satisfied with practical } \\
\text { curriculum }\end{array}$} & Yes & $3(0.78)$ \\
\hline & No & $384(99.22)$ \\
\hline \multirow{4}{*}{$\begin{array}{l}\text { How much time would } \\
\text { be sufficient to cover for } \\
2^{\text {nd }} \text { professional MBBS }\end{array}$} & 1 year & $163(42.11)$ \\
\hline & 2 years & 0 \\
\hline & $1 \frac{1}{2}$ years & $194(50.13)$ \\
\hline & Can’t say & $30(07.75)$ \\
\hline \multirow{2}{*}{$\begin{array}{l}\text { Preparing and dispensing } \\
\text { exercise in pharmacy } \\
\text { practical }\end{array}$} & Yes & $291(75.19)$ \\
\hline & No & $96(24.81)$ \\
\hline \multirow{2}{*}{$\begin{array}{l}\text { Usefulness of preparing } \\
\text { and dispensing exercise }\end{array}$} & Yes & $87(22.48)$ \\
\hline & No & $300(77.51)$ \\
\hline \multirow{2}{*}{$\begin{array}{l}\text { Should preparing and } \\
\text { dispensing exercise } \\
\text { continued }\end{array}$} & Yes & $343(88.63)$ \\
\hline & No & $44(11.37)$ \\
\hline \multirow{3}{*}{$\begin{array}{l}\text { Prepared medicine in } \\
\text { pharmacy exercise is } \\
\text { given to needy patients }\end{array}$} & Yes & $0(0)$ \\
\hline & No & $374(96.64)$ \\
\hline & Can’t say & $13(3.36)$ \\
\hline \multirow{2}{*}{$\begin{array}{l}\text { Have you visited animal } \\
\text { house of own institute }\end{array}$} & Yes & $96(24.81)$ \\
\hline & No & $291(75.19)$ \\
\hline \multirow{3}{*}{$\begin{array}{l}\text { Animal should be used } \\
\text { for UG teaching }\end{array}$} & Yes & $101(26.09)$ \\
\hline & No & $241(62.27)$ \\
\hline & Can’t say & $45(11.63)$ \\
\hline \multirow{2}{*}{$\begin{array}{l}\text { Is practical curriculum } \\
\text { fulfilling the objectives }\end{array}$} & Yes & $0(0)$ \\
\hline & No & $387(100)$ \\
\hline
\end{tabular}


Table 1: (Continued).

\begin{tabular}{|c|c|c|}
\hline Questions for opinion & Response & $\mathbf{N}(\%)$ \\
\hline \multirow{3}{*}{$\begin{array}{l}\text { Usefulness of CAL in } \\
\text { experimental teaching } \\
\text { for UG }\end{array}$} & Yes & $244(63.05)$ \\
\hline & No & $22(5.68)$ \\
\hline & Can’t say & $121(31.27)$ \\
\hline \multirow{3}{*}{$\begin{array}{l}\text { Usefulness bedside } \\
\text { teaching in pharmacology } \\
\text { in } 2^{\text {nd }} \mathrm{MBBS}\end{array}$} & Yes & $288(74.42)$ \\
\hline & No & $46(11.89)$ \\
\hline & Can’t say & $53(13.69)$ \\
\hline \multirow{3}{*}{$\begin{array}{l}\text { Inclusion of PBL/case } \\
\text { based study in practical } \\
\text { classes }\end{array}$} & Yes & $349(90.18)$ \\
\hline & No & $8(2.07)$ \\
\hline & Can’t say & $30(7.75)$ \\
\hline
\end{tabular}

PBL: Problem-based learning, CAL: Computer assisted learning, UG: Undergraduate

More than $75.19 \%$ of the students were preparing and dispensing emulsions, mixtures, lotions, etc. during pharmacy practical classes. Dispensing and preparation exercises were graded as irrelevant in today's clinical practice according to $87.78 \%$ of the students, since in the current scenario, dispensation of factory manufactured drugs by medical shops is the norm. As reflection of this viewpoint by $88.63 \%$ of the students were in favor of the deletion of such exercises from the curriculum. All students who were included in the study were of the firm belief that present practical curriculum was unable to meet the objective of pharmacology teaching in 2nd MBBS and they wanted a more clinically oriented approach. About 59.94\% students have opted for pharmacology as the most important subject amongst 1st and 2nd MBBS subjects because of its relevance in today's clinical practice (Figure 1) while according to $47.27 \%$ of the students it has the most boring and least useful practical classes (Figure 2).

Analysis showed that $62.27 \%$ of the students were of the opinion that animals should not be used in experimental pharmacology for UG teaching while a minority (11.62\%) was undecided. Only about one-fourth students had seen an animal house in their institute.

More than half of the students (63\%) supported the use of computer-assisted learning (CAL) for experimental teaching and more than one-third of the students $(33.33 \%)$ were unable to express a definite view in this regards while very few $(3.67 \%)$ of them were against the use of such learning methods (Figure 3). About half of the students had felt pharmacology as the most interesting branch amongst all the 1st and 2nd MBBS subjects. Three-fourths of the students who participated in the survey believed that an adequate knowledge of pharmacology was very much necessary to become a good doctor and that the subject was interesting

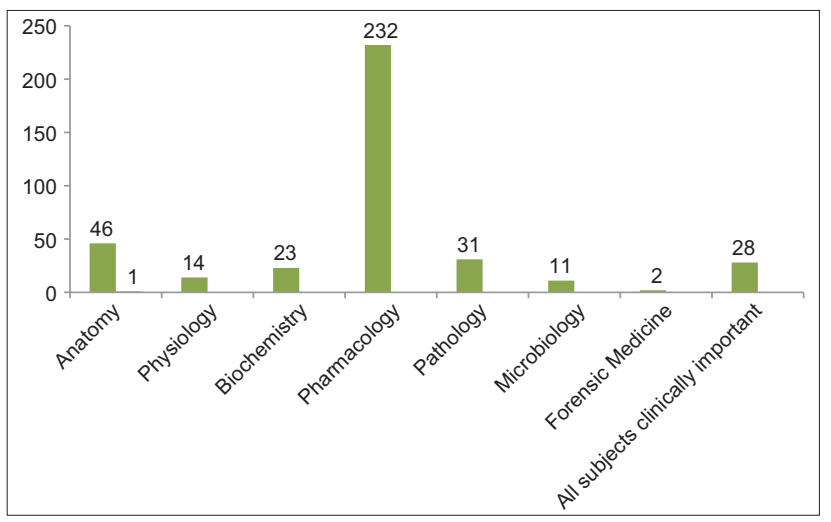

Figure 1: The most important subject in I and II MBBS in today's clinical practice as student's view.

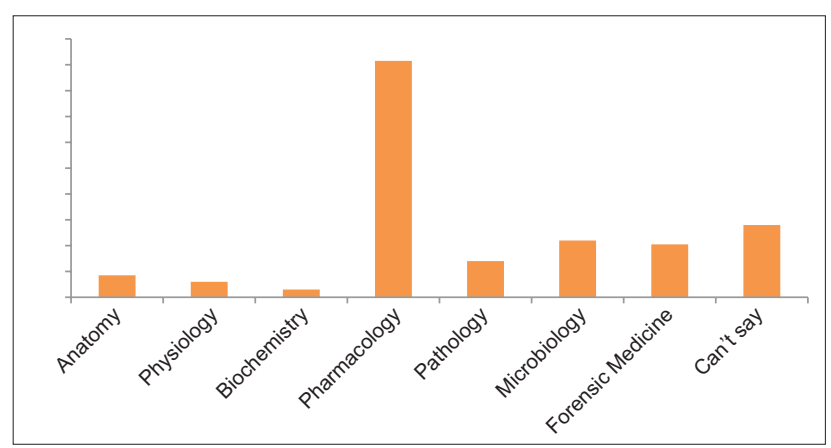

Figure 2: The most boring and least useful practical classes in I and II MBBS subjects.

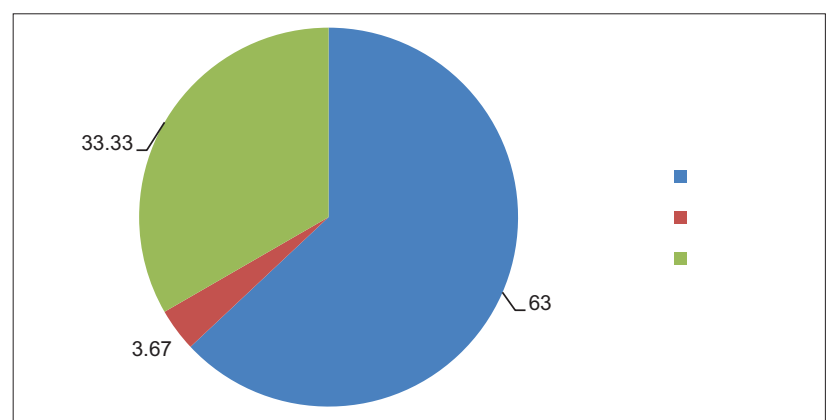

Figure 3: Students opinion about usefulness of computer assisted learning in experimental teaching for undergraduates.

for reading, but difficult in understanding. Pharmacology should not be taught in or after 3rd MBBS according to $78.28 \%$ of them.

The students were differed in their opinion regarding bedside pharmacology teaching. We found that $48.57 \%$ and $74.41 \%$ of the students were in favor of inclusion after and during 2nd MBBS, respectively. Some students are unable to say anything about bedside teaching (Figure 4), among them only few $(4.39 \%)$ have reported adverse drug reaction (ADR) or filled ADR report forms. Much lesser number of students $(1.21 \%)$ had assessed the prescriptions for their rationality on the basis of standards treatment guidelines during the course of their clinical postings. 
$62 \%$ of the respondents were of the opinion that blackboard teaching in addition to the use of audio-visual aids were the most effective tool for giving lectures and around one-fourth $(24.80 \%)$ were satisfied with the conventional teaching methods, while the least number $(13.17 \%)$ of them were satisfied with an audio-visual lecture only (Figure 5). All of the students were interested in the inclusion of case, problem and multiple choice based question discussions in regular teaching classes followed by quizzes $(31.78 \%)$ and group discussions (14\%), while least number of students (1.03\%) were interested in the conduction of seminars (Figure 6). $70 \%$ of the candidates were studying the subject with the combined use of lecture notes and textbooks while around $19 \%$ and $1.5 \%$ of the student were studying only with help of either textbooks or lecture notes respectively. Some of the students were reading multiple choice questions (MCQ) based books and concise books with the purpose of passing exams easily. Regular tests, viva and tutorials were the reasons for studying pharmacology regularly among approximately $90 \%$ of the students followed by qualifying pre postgraduate (MCQ) exams (19.63\%), gaining more knowledge (11.37\%), passing the 2nd professional exam $(10.59 \%)$ and due to interest (5.16\%) (Figure 7). All students

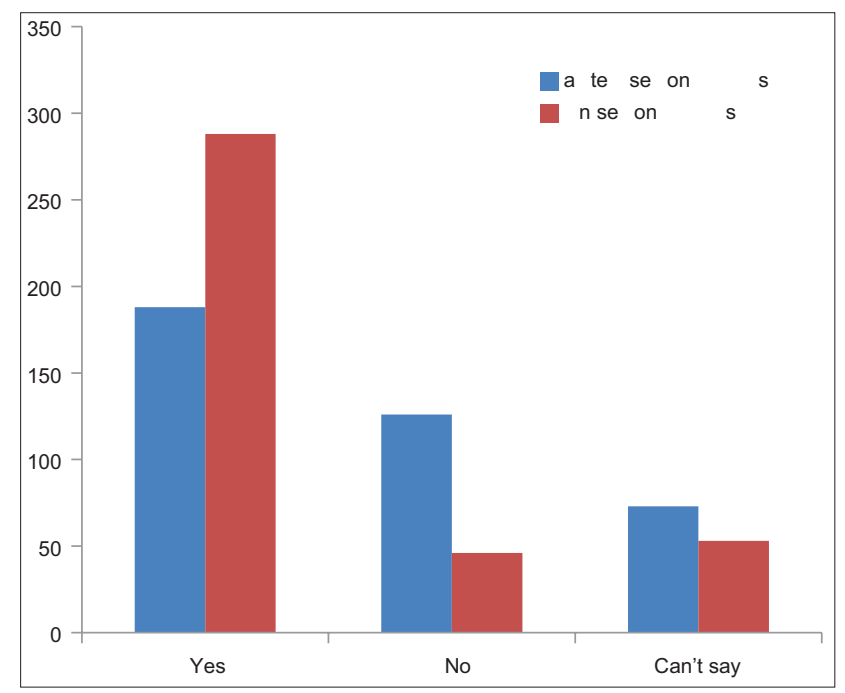

Figure 4: Students view about bedside teaching by pharmacologist in and after 2nd MBBS.

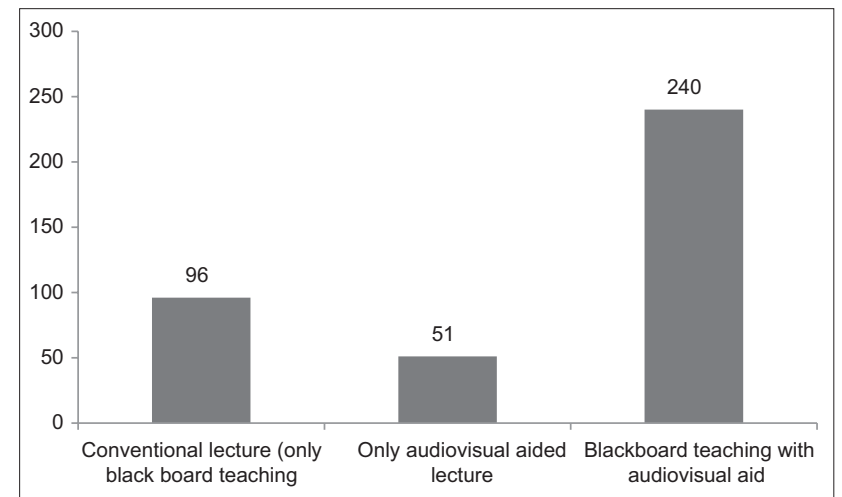

Figure 5: The most effective method of teaching by lecture. have suggested that emphasis should give the training in clinical pharmacology.

\section{DISCUSSION}

In the present survey, it was observed that there was very high level of un-satisfaction among medical UG students with regard to pharmacology practical curriculum. The pharmacology practical is mainly divided into two main sections pharmacy (dispensing) and experimental pharmacology. Our study reflected reforms in both sections. The UG medical students of All India Institute Medical Science, New Delhi protested against the outdated practical curriculum which was being followed at their institute. ${ }^{2,5}$ Unfortunately, still such types preparing and dispensing emulsion, mixtures, lotions, etc. like exercises are being taught in many medical colleges of our country. Although MCI has modified curriculum and clear cut direction of teaching and learning methodology in regulation on graduate medical education in 2012, called Vision 2015, but it is not implemented till date. In our survey, three out of four medical colleges were following pharmacy exercises. Although premier institutes and all medical colleges of Gujarat have

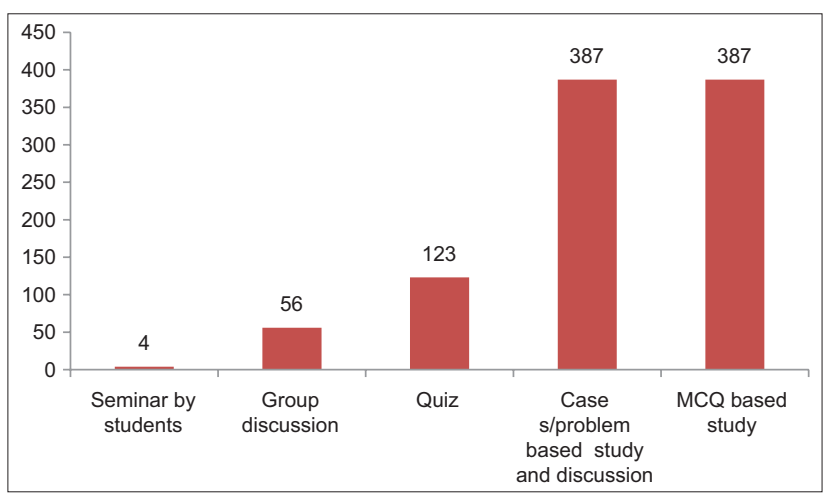

Figure 6: Methods to be added as a part of regular teaching to make subject more interesting and useful (students have liberty to give more than one opinions).

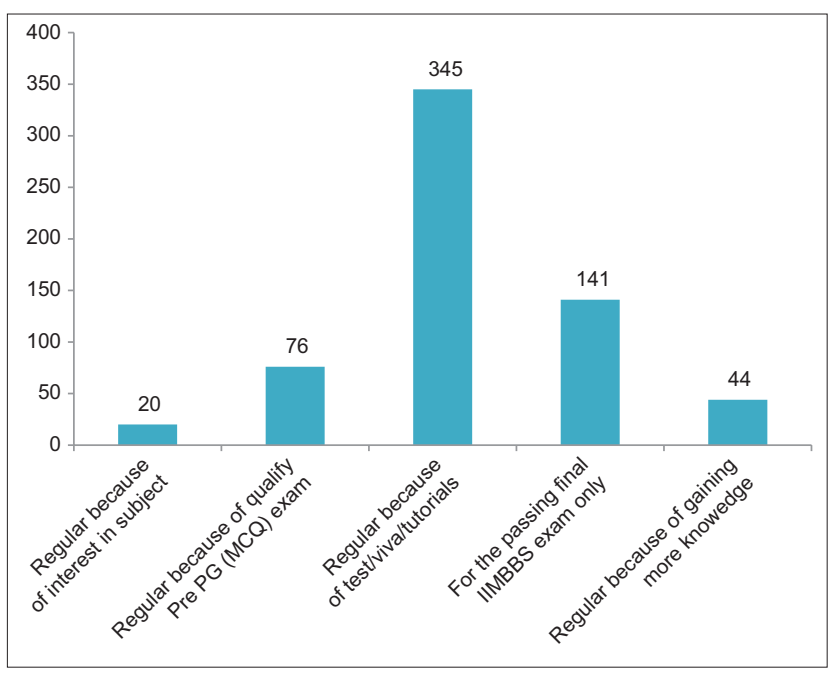

Figure 7: Study pattern of pharmacology. 
suitablymodified practical teaching by their own efforts but it is urgently need to be implemented at all medical colleges. However, it is not possible until reforms are made in the graduate medical curriculum of MCI because we are bound to follow the UG curriculum. ${ }^{6}$

In the experimental pharmacology section, presently, rabbit eye experiment for unknown and known drugs, some intact animal experiments and some important charts and graphs are taught in the majority of medical college. Again syllabus of experimental practical needs to be modified as bioassay and other invasive method now lost its relevance for UG medical students. The MCI has taken positive direction in this regard, now animal house is not mandatory for UG teaching. More than $60 \%$ of the students were of the opinion that animals should not be used in experimental pharmacology for UG teaching while $63 \%$ supported CAL. Presently more than half of instruments which are essentials for MCI permission for starting graduate course remain unutilized. Unfortunately, the currently animal experiments miserably fail to achieve the stated objectives. So, an emerging trend as an alternative to the animal experiments is the use of computer simulated experiments and CAL. These have several advantages of CAL, lesser involvement and time and labor, high feasibility, and effective in understanding, more cost effective, repeatability, sharing of information and no ethical issue. Our results were in contrast to those of a study which was conducted in three medical colleges of north India in $2005,{ }^{7}$ but they were supported by the results of an Australian study which was done for computer stimulated pharmacology experiments for UG pharmacy students. ${ }^{8}$

About half of the UG students (47.26\%) opted for the most boring and least useful practical classes among the basic science subjects so our responsibility to make practical classes more useful and interesting. Around three fourth of the students expressed that bedside teaching of pharmacology should be included in during 2nd MBBS but only $48.5 \%$ were in it being after 2nd MBBS. However, $73.20 \%$ interns suggested that apart from 2nd MBBS it should be included in 3rd MBBS curriculum in another research. ${ }^{9}$ Similarly, a study which was conducted in New Delhi India has showed that $80.47 \%$ students and $87.50 \%$ teachers were in of bedside teaching. ${ }^{10}$ It was also noted that blackboard teaching with audio-visual aids liked by $62 \%$ (240/387) of the students. Small group teaching with a strict bilateral communication was the first preferences of a majority of the students as it encourage the student's involvement in lecture which may improves their performance in exams. The students expressed more need of case or problem-based studies, clinical orientations innovative teaching programs group discussions and tutorials in regular teaching, but they least liked seminar by them as was observed in other studies also. ${ }^{11,12}$ We should try to make the seminars more interesting. The suggestions of relevant modifications in the current curriculum pharmacology made by Indian Pharmacology Society and in various research publications time to time. ${ }^{1,13-20}$ The Students' feedback is guide for the teachers for modifying the teaching methodologies for planning curriculum in order to make pharmacology more meaningful to them. MCI is going to implement Vision 2015, it has many innovative things, e.g. small group teaching is allotted $138 \mathrm{hrs}$, whereas only $80 \mathrm{hrs}$ for interactive lecture, competency-based education, curriculum as per need of present scenario, etc. This would be positive step by apex regulator of medical education it may solve many of our problems. ${ }^{6,20}$

\section{CONCLUSION}

On the basis of the results of the present survey, we conclude that it is very important to know the needs of our students, whether they were well motivated and interested in grasping the knowledge which is included in vast course in a limited time and getting the requisite skills for selecting appropriate drugs for particular patients. The student's feedback is guides for the teacher for modifying the teaching methodologies and for planning curriculum to make pharmacology more meaningful to them. It is only possible when we remove useless things by adding the current topic and follow innovative teaching methods.

Funding: No funding sources

Conflict of interest: None declared

Ethical approval: The study was approved by the Institutional Ethics Committee

\section{REFERENCES}

1. Desai M. Changing face of pharmacology practicals for medical undergraduates. Indian $\mathrm{J}$ Pharmacol. 2009;41(4):151-2.

2. Gitanjali B. New wine in new bottles. Indian J Pharmacol. 2004;36:63-4.

3. Ruth N. Communicating student evaluation of teaching results: rating interpretation guides (RIGs). Assess Eval High Educ. 2000;25(2):121-34.

4. Victoroff KZ, Hogan S. Students' perceptions of effective learning experiences in dental school: a qualitative study using a critical incident technique. J Dent Educ. 2006;70(2):124-32.

5. AIIMS students unhappy with archaic syllabus. Times of India. $2004 \mathrm{Feb}, 20$. Available at http://timesofindia. indiatimes.com/topic/Aiims Students Unhappy With Archaic Syllabus.

6. Medical Council of India regulation on graduate medical education 1997. New Delhi: Medical Council of India. Available at http://www.mciindia.org/Rulesand-Regulation/GME_REGULATIONS.pdf. Accessed 04 June 2015.

7. Medhi B, Sukhija M, Upadhayay S, Bhatia A, Anuradha K. Experimental teaching and interactive computer assisted learning: the students point view. JK Sci. 2005;7(4):220-2.

8. Wang L. Computer-stimulated pharmacology experiments for undergraduate pharmacy students: experience from an Australian university. Indian J Pharmacol. 2001;33:280-2.

9. Akat PB, Karande VB, Murthy MB, Burute SR. Interns opinion on 'bedside pharmacology clinics' and its 
incorporation in undergraduate curriculum. J Pharmacol Pharmacother. 2012;3(1):56-8.

10. Kela AK, Mehta VL. Impact of inclusion of clinical projects in undergraduate teaching. Indian $\mathrm{J}$ Pharmacol. 1993;25(4):249-50.

11. Garg A, Rataboli PV, Muchandi K. Students' opinion on the prevailing teaching methods in pharmacology and change recommended. Indian J Pharmacol. 2004;36(3):155-8.

12. Chadav N, Yadav P, Chaudhri M, Kantharia ND. Second year student's feedback on teaching methodology and evaluation methods in pharmacology. Natl J Physiol Pharm Pharmacol. 2011;1(1):23-31.

13. Hariharan TS. Need for the changes in the practical pharmacology curriculum of medical graduates. Indian $\mathrm{J}$ Pharmacol. 2004;36(3):181.

14. Sharma R, Verma U, Kapoor B, Chopra VS. Novel teaching approaches in pharmacology. JK Sci. 2004;6(3):172-3.

15. Bhavsar VH. Experience regarding modification of the teaching and evaluation pattern in practical pharmacology. Indian J Pharmacol. 2004;36:385-9.
16. Mathur VS. Towards a more meaningful teaching a pharmacology. Indian J Pharmacol. 2004;36:258-61.

17. Kausal S, Chopra SC, Arora S. Modifications in the undergraduate MBBS pharmacology practical curriculum: the DMCH model. Indian J Pharmacol. 2007;39:57-9.

18. Sharma V, Sharma R. Pharmacolgy teaching: Need for a sea change. Indian J Pharmacol. 2009;41(6):288.

19. Joshi A, Trevedi M. Innovation in pharmacology teaching. Int J Pharm Biomed Res. 2010;1(2):62-4.

20. Naeem SS, Rizvi W, Kumar A. Revisiting undergraduate practical pharmacology. J Pharmacol Pharmacother. 2012;3(1):76-9.

Cite this article as: Saurabh MK, Agrawal J. The opinion of undergraduate medical students on current curriculum and teaching methodology of pharmacology in four medical colleges of India: a questionnaire based study. Int J Basic Clin Pharmacol 2015;4:970-5. 